\title{
Correction to: River to river: First evidence of eel movement between distant rivers via the sea
}

\author{
Manabu Kume (D) Naoki Nakayama - Yasunari Iwasaki • Tomoya Hori (D) \\ Shun Watanabe (iD) Yuki Terashima $\cdot$ Ayano Medo $\cdot$ Nobuaki Arai • \\ Yoh Yamashita (D) Hiromichi Mitamura
}

Published online: 10 June 2021

(C) Springer Nature B.V. 2021

\section{Correction to: Environ Biol Fish (2021) 104(4):529-533 https://doi.org/10.1007/s10641-021-01090-y}

The original published version of this article contained errors in the third paragraph (p. 530). Details on those errors and related corrections are provided here. One tagged eel released in St. 8 was mistakenly put into the data released in St. 7. The corrected text is:

Eight (ID28-35 [mean \pm standard deviation $=478 \pm 57 \mathrm{~mm}$ total length (TL)]) and seven eels
(ID21-27 [475 $\pm 56 \mathrm{~mm}$ TL]), which were randomly selected, were released at lower (St. 7; Fig. 1c) and upper (St. 8; Fig. 1d) reaches of the weir on 8 April 2019, and were monitored until 15 July 2020.

Publisher's note Springer Nature remains neutral with regard to jurisdictional claims in published maps and institutional affiliations.

The original article can be found online at https://doi.org/ 10.1007/s10641-021-01090-y.

M. Kume $(\bowtie) \cdot$ N. Arai · Y. Yamashita $\cdot$ H. Mitamura Field Science Education and Research Center, Kyoto University, Kitashirakawa-Oiwake, Sakyo, Kyoto 606-8502, Japan

e-mail: kume.manabu.6x@kyoto-u.ac.jp

N. Nakayama · A. Medo

Graduate School of Informatics, Kyoto University,

Kyoto 606-8501, Japan

Y. Iwasaki

Graduate School of Global Environmental Studies, Kyoto

University, Kyoto 606-8501, Japan

T. Hori

Graduate School of Education, Kyoto University,

Kyoto 606-8501, Japan

\author{
S. Watanabe \\ Faculty of Agriculture, Kindai University, Nara 631-8505, \\ Japan \\ Y. Terashima $\cdot$ Y. Yamashita \\ Research and Educational Unit for Studies On \\ Connectivity of Hills, Humans and Oceans, Kyoto \\ University, Kyoto 606-8502, Japan \\ N. Arai \\ National Fisheries University, Yamaguchi 759-6595, Japan \\ H. Mitamura \\ Graduate School of Agriculture, Kyoto University, \\ Kyoto 606-8501, Japan
}

